\title{
Escenarios estadísticos del COVID-19 en Honduras: análisis desde la inteligencia de negocios y la transparencia de datos
}

\author{
Statistical scenarios of COVID-19 in Honduras: analysis from the business intelligence and data transparency \\ perspective \\ Efraín Farach, ${ }^{\mathrm{a}, 1}$ Aldo Romero ${ }^{\mathrm{b}}$ \\ ${ }^{a}$ Inteligencia de Negocios, Tegucigalpa, Honduras \\ ${ }^{b}$ Centro Universitario Tecnológico CEUTEC de UNITEC, Tegucigalpa, Honduras
}

\author{
Historia del artículo: \\ Recibido: 28 agosto 2020 \\ Revisado: 28 agosto 2020 \\ Aceptado: 30 agosto 2020 \\ Publicado: 30 agosto 2020 \\ Palabras clave \\ Pandemia \\ COVID-19 \\ Tratamiento de datos \\ Plataformas \\ Riesgos \\ Necesidades de visualización \\ Keywords \\ Pandemic \\ COVID-19 \\ Data treatment \\ Platforms \\ Risks \\ Display needs
}

\begin{abstract}
RESUMEN. Introducción. Los datos oficiales sobre el COVID-19 en Honduras son publicados a diario por el gobierno vía Sistema Nacional de Gestión de Riesgos (SINAGER). Método: Se dio tratamiento manual de los datos, subsanando frecuentes inconsistencias acudiendo a fuentes primarias (sistema de salud y municipalidades). Se usó herramientas de Inteligencia de Negocios para el modelamiento y visualización de datos con Power BI Desktop. Resultados: Al 28 de agosto de 2020 había 58,810 casos confirmados por RTPCR, con edad promedio de 39.8 años (rango 21-40 años) y 53\% hombres. El $28.6 \%$ del total fueron reportados en agosto, pero extemporáneos por retraso por limitaciones laboratoriales. Hubo 1,827 muertes por COVID19, con edad promedio de 62.4 años, $65 \%$ hombres, $48 \%$ entre 51 a 70 años de edad. El $33.1 \%$ de los casos y $36.2 \%$ de las defunciones eran de Cortés, seguido por Francisco Morazán y aumentando progresivamente en otros departamentos. Discusión: Sólo $1.5 \%$ de la población se ha realizado RT-PCR. Al 28 de agosto se redujo en $24.4 \%$ el número de casos, asociado a una reducción de realización de pruebas de $29.2 \%$ respecto a meses previos. La tasa de positividad en agosto $(45.5 \%)$ es la más alta en Centroamérica. Conclusión: A pesar del limitado acceso a RT-PCR, los datos oficiales sobre COVID-19 en Honduras muestran una curva ascendente en agosto, expandiéndose al interior del país. Se propone dar más acceso a datos abiertos de mayor calidad e innovar agregando inteligencia de negocios para luchar contra esta pandemia.
\end{abstract}

\begin{abstract}
Introduction: Official data on COVID-19 in Honduras is published daily by the government via the National Risk Management System (SINAGER). Method: Data was curated manually, correcting for frequent inconsistencies by consulting primary sources (health system and municipalities). Business Intelligence tools were used for data modeling and visualization using Power BI Desktop. Results: As of August 28, 2020, there were 58,810 cases confirmed by RT-PCR, average age of 39.8 years (range 21-40 years), $53 \%$ were men. Interestingly, $28.6 \%$ of all cases were reported in August, extemporary by several weeks late due to laboratory limitations. There were 1,827 deaths from COVID-19, average age of 62.4 years, $65 \%$ were men, $48 \%$ were between 51 to 70 years of age; $33.1 \%$ of all cases and $36.2 \%$ of deaths were from the Department of Cortés, followed by Francisco Morazán and progressively increasing in other departments. Discussion: Only $1.5 \%$ of the population has undergone RT-PCR. As of August 28, the number of cases was reduced by $24.4 \%$, but associated with $29.2 \%$ reduction in lab testings done, compared to previous months. The positivity rate in August (45.5\%) is the highest in Central America. Conclusion: Despite limited access to RT-PCR, official data on COVID-19 in Honduras shows an ascending curve in August, expanding into the rural regions. We propone to give access to open data of higher quality and to innovate with business intelligence to fight this pandemic.
\end{abstract}

\section{Introducción}

La epidemia por el coronavirus llamado SARS-CoV-2 inició en China a finales del 2019, causando miles de casos de COVID-19 (Coronavirus Disease 2019) en ese país y luego en todo el mundo (Weng et al., 2020; Johns Hopkins University, 2020). La Secretaría de Salud (SESAL) de Honduras confirmó el primer caso de COVID-19 el 10 de marzo de 2020 (Despacho de Comunicaciones y Estrategia Presidencial Honduras, 2020). Posteriormente, se vio el aumento de contagios y muertes por la enfermedad en las

\footnotetext{
1 Autor corresponsal: efrainfarach@gmail.com, Inteligencia de Negocios, Tegucigalpa, Honduras Disponible en https//doi.org/10.5377/innovare.v9i2.10193

(C) 2020 Autores y UNITEC. Este es un artículo de acceso abierto según licencia http://creativecommons.org/licenses/by-nc-nd/4.0
} 
ciudades grandes (Zúniga-Moya, et al., 2020), que se extendió pronto a los 18 departamentos del país. Inicialmente se reportó una aparente tasa de letalidad superior a lo observado en otros países y se fue observando una curva atípica de casos a medida que se hacía más o menos pruebas de acuerdo a la capacidad laboratorial instalada (PAHO/WHO, 2020; OPS, 2020).

Los estudios y pronósticos epidemiológicos iniciales advirtieron que para los meses de junio, julio y agosto, al menos los 500 mil hondureños estarían afectados por el virus COVID-19, en los medios de comunicación nacionales los expertos destacaron que por cada caso confirmado existen 10 más que no se han identificado pero que son parte de su núcleo cercano. Si esto es así, las cifras oficiales basadas en pruebas diagnósticas de poco acceso, no reflejan la realidad (Expediente Público, 2020). Desde los inicios de la pandemia a la fecha, se viene arrastrando un desfase de entre 4 a seis semanas en los resultados de las pruebas diagnósticas específicas RT-PCR y esto lo reconocieron las propias autoridades del Laboratorio Nacional de Virología de la Secretaria de Salud (Hola News, 2020). Esta situación limita el control estadístico y se convierte también en una gran limitante para médicos, pacientes y familiares, presas de la incertidumbre a falta de un diagnóstico oportuno.

¿Cuántas pruebas se realizan? Esta es otra gran limitante, Honduras es el país de Centro América con la segunda mayor población afectada, el que menos pruebas diarias realiza en el campo y a la vez el que menos procesa a nivel de laboratorio. Esto impide saber a ciencia cierta el número de contagios, los casos reales y los diagnósticos específicos. De igual forma, imposibilita conocer el real momento de la pandemia y cuándo llegaremos al pico o a la etapa de aplanar la curva. ¿Por qué son importantes la transparencia, pertinencia y la disposición oportuna en las estadísticas en las emergencias sanitarias como la actual? En medio de una crisis tan profunda como la que actualmente viven los hondureños, la información es primordial. Contar con números reales puede marcar la diferencia en el manejo sanitario, así como para una ciudadanía que se debate en los extremos, los que se cuidan y los que se exponen.

Este reporte presenta un análisis de los principales indicadores y métricas que pueden generarse sobre la pandemia del COVID-19 en Honduras, tomando como fuente las cifras oficiales brindadas mediante los comunicados diarios que ofrece el Sistema Nacional de Gestión de Riesgos (SINAGER, 2020; Secretaría de Salud, 2020). Adicionalmente, se han investigado todos los datos con oportunidad de revisión para modelar los escenarios comparativos y predictivos que genera el virus en Honduras

\section{Métodos}

\subsection{Fuente y curado de los datos}

El origen de los datos son los comunicados que genera el Estado por medio de las cadenas nacionales diarias, cuando se presentan los resultados procesados ese día. Seguidamente se procedía a tabular, integrar y procesar cada dato y se le aplicaba un mantenimiento manual a las sabanas de datos que alimentamos todos los días. Fue complejo pegarse directamente de la fuente primaria por no ser compatible y a la vez presentar diversas inconsistencias, que al ser identificadas por discordancias en los rangos de edad, sexo, departamento, municipio y cantidad, se corregían gracias a fuentes externas o complementarias (documentos autorizados, oficinas de hospitales públicos, municipalidades, enlaces relacionados y consultas a médicos informados del tema).

\subsection{Definiciones importantes}

Se considera casos a los pacientes con o sin síntomas de COVID-19 que tienen una prueba RT-PCR positiva. Los casos recuperados por COVID-19 en Honduras se manejan de acuerdo con criterios de clínica, el país no cuenta con un protocolo de definición y seguimiento a estos casos, recién las autoridades sanitarias del país anunciaron en conferencia de prensa que se identifica como tal a todo paciente leve o asintomático que después de 14 días no presente evolución en la enfermedad (OPS, 2020; Secretaría de Salud, 2020).

\subsection{Métodos de análisis y visualización}

Teniendo los datos normalizados y con la menor cantidad de inconsistencias posibles nos apoyamos en herramientas de análisis para proceder con la última etapa del proceso en Inteligencia de Negocios que es la del modelamiento y visualización de los datos. Para esta etapa identificamos las necesidades de información que es preciso mostrar y los objetos visuales que mejor se acomoden para una mejor lectura y comprensión por parte de los usuarios. La herramienta utilizada para ese fin fue Power BI Desktop por ser más dinámica y con mejor alcance visual, además de ser de acceso abierto (Microsoft, 2020).

\section{Resultados}

\subsection{Casos en general}

Al 28 de agosto, los boletines de SINAGER indicaban que se había confirmado por RT-PCR un total de 58,810 casos, con una edad promedio de 39.8 años y con una proporción es $53 \%$ hombres y $47 \%$ mujeres (Figura 1a). El $47.8 \%$ de estos casos tenía edades comprendidas entre 2140 años. El $28.56 \%$ del total de los casos fueron reportados en el mes de agosto.

\subsection{Mortalidad}

Hubo un total de 1,827 muertes confirmadas con una edad promedio de 62.4 años donde la proporción fue $65 \%$ 
hombres y $35 \%$ mujeres. El $48.06 \%$ de estas muertes son edades comprendidas entre 51-70 años. El 26.82\% del total de las muertes corresponden al mes de agosto (Figura 1b).

\subsection{Casos recuperados}

Las estadísticas reportan un total de 10,076 personas recuperadas confirmadas por la SESAL, con edad promedio de 37.8 años, $52 \%$ hombres y $48 \%$ mujeres, distribución por sexo que está acorde a los casos confirmados. El $53.5 \%$ de estos recuperados son edades comprendidas entre 21-40 años. El $44.8 \%$ del total de los recuperados se reportaron en el mes de agosto (Figura 2).

\subsection{Distribución geográfica de los casos}

A la fecha, el departamento de Cortés presenta mayor participación en casos (33.11\%), muertes (36.29\%) y recuperados (46.47\%). Le sigue Francisco Morazán y así sucesivamente el resto de los departamentos (Figura 2).

\subsection{Pruebas aplicadas y su tasa de positividad}

Se han aplicado en el periodo del informe un total de 141,059 pruebas para detectar COVID-19 y la tasa de positividad histórica es del $41.69 \%$ (desde que inicio la pandemia en Honduras) (Figura 3).

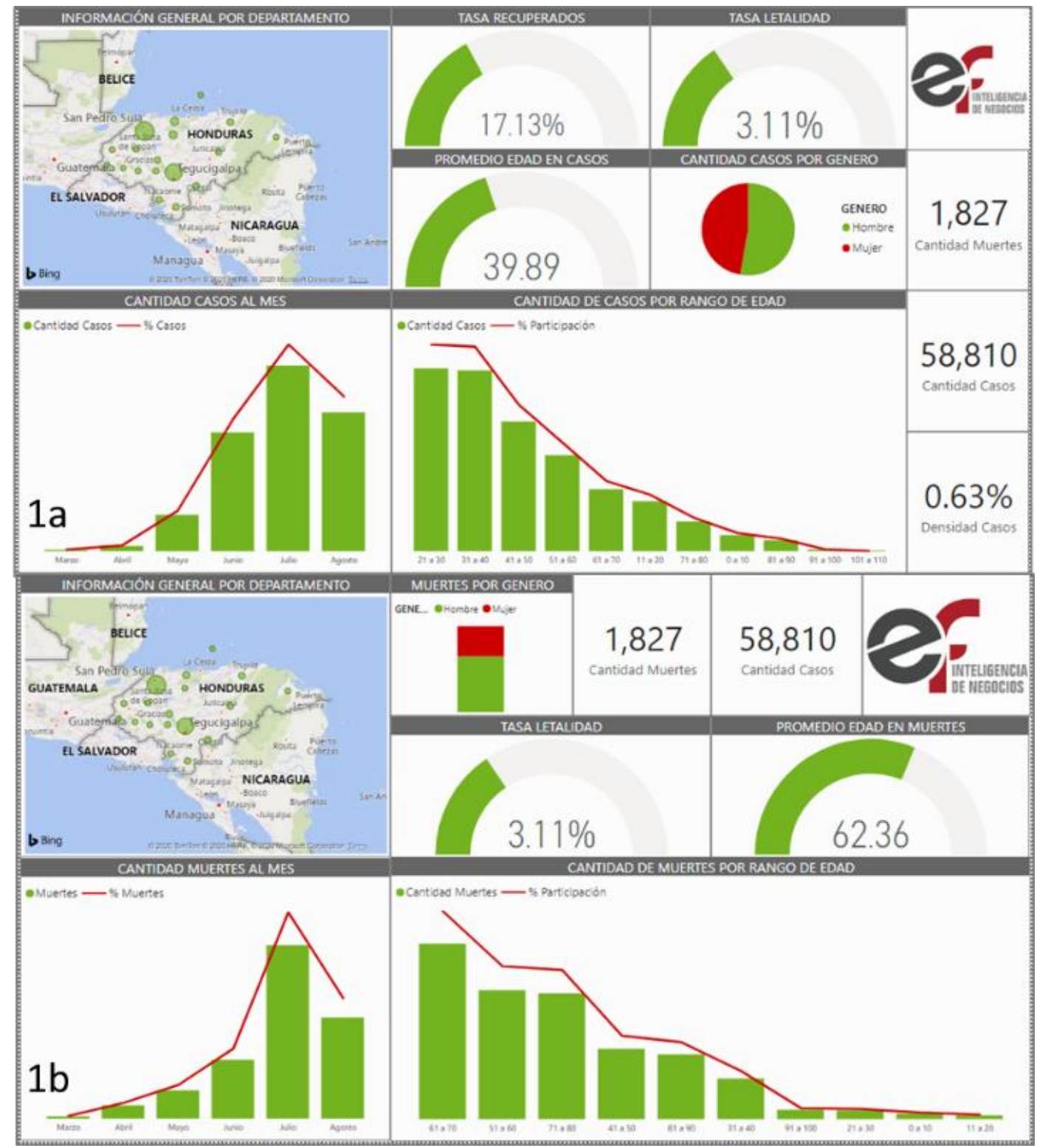

Figura 1. Casos de COVID-19 y mortalidad a nivel nacional. Representación a partir de los datos por SINAGER. 


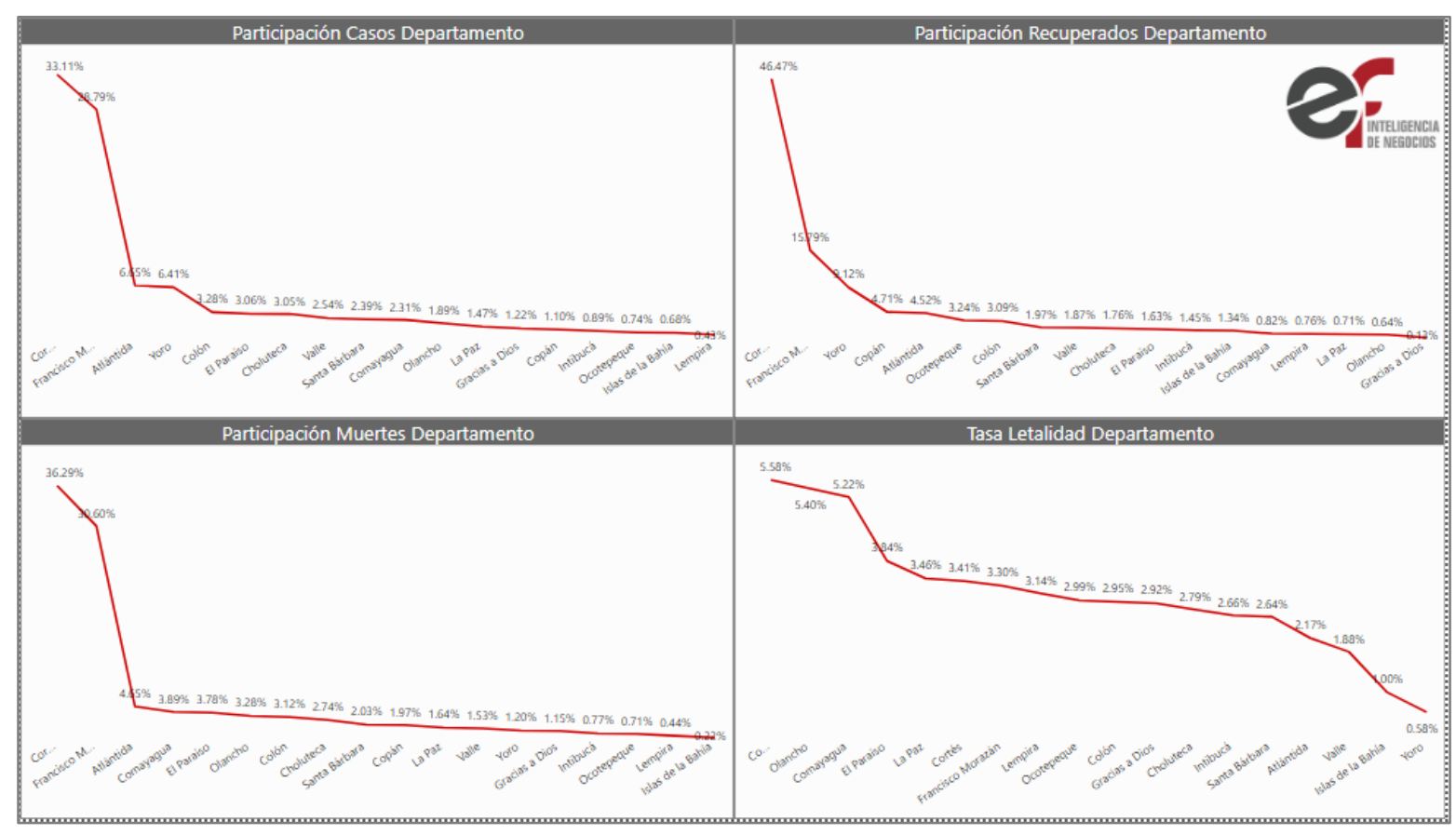

Figura 2. Participación geográfica por departamentos.

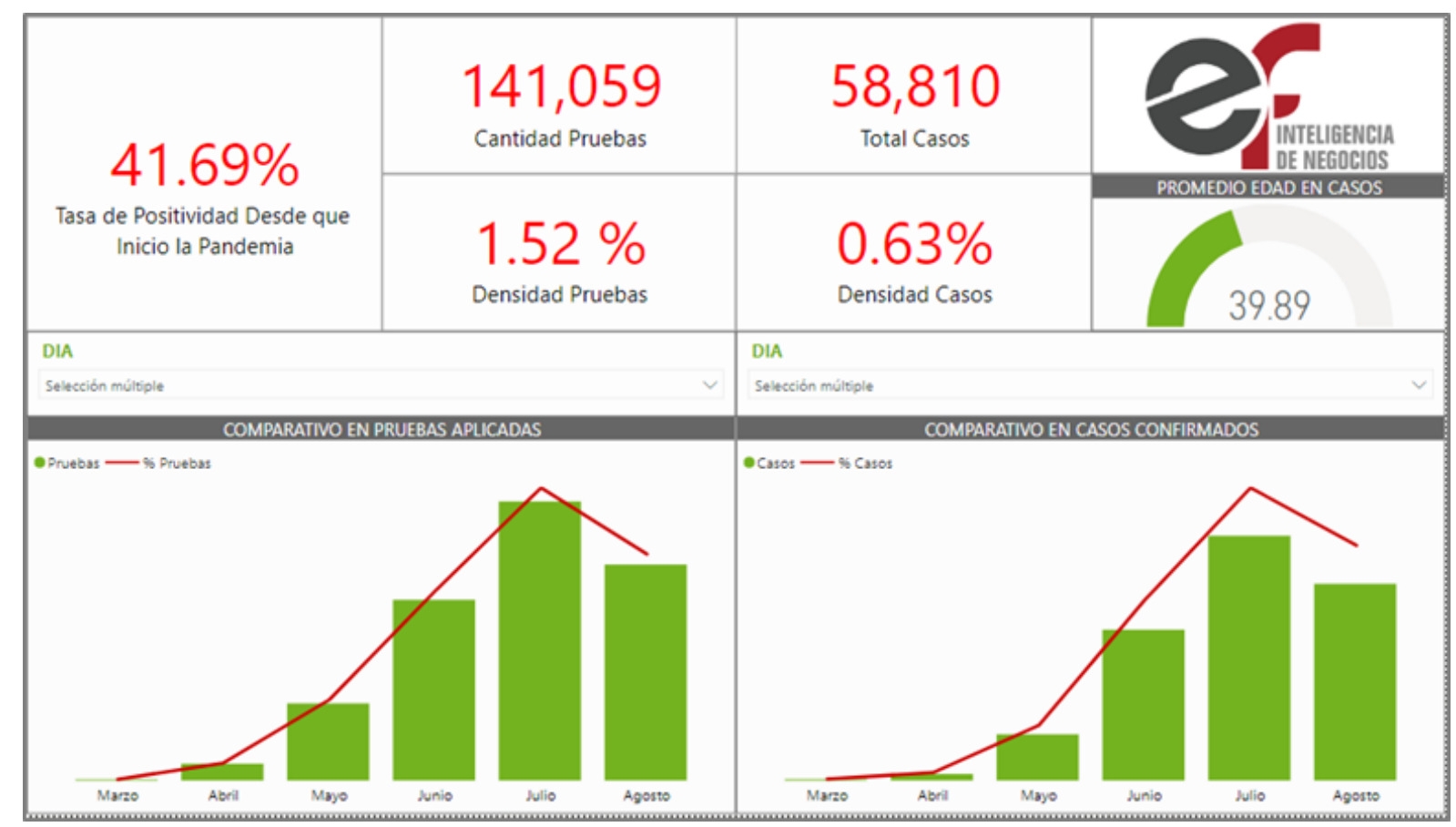

Figura 3. Control en pruebas aplicadas y tasa de positividad. 
Cabe notar que solamente al $1.5 \%$ de la población se le han practicado pruebas para detección del virus. En los 28 días del mes de agosto contra el mismo periodo en julio, se presenta una reducción de casos del $24.4 \%$ y esto se debe a que en ese rango de tiempo se han aplicado un $29.2 \%$ pruebas menos. La tasa de positividad en agosto alcanzó el 45.5\%, la más alta en la región Centroamericana.

\subsection{Tasa de letalidad}

La tasa de letalidad es encabezada actualmente por los departamentos de Copán (5.6\%) y Olancho (5.4\%). Se presentó en los siguientes rangos de edad: 61-70 años con una tasa del $10.53 \%, 71-80$ años con $15.80 \%$ y $81-90$ años con $22 \%$ (Figura 4). Se ha considerado que mucha población joven se está infectando y poniendo en riesgo a la población vulnerable (adultos mayores y personas con enfermedades de base), siendo el riesgo mayor cuando muchos de estos casos jóvenes son asintomáticos. Esta relación no pudo ser determinada por los datos disponibles.

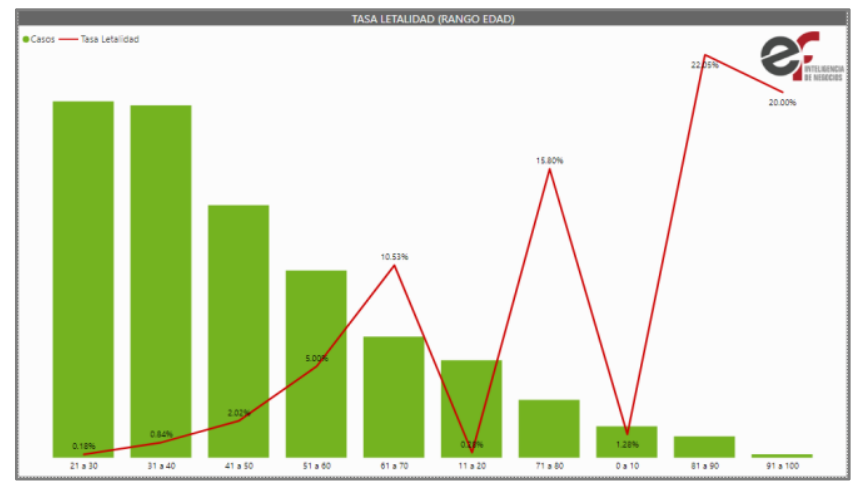

Figura 4. Intervalos de edad en casos con su respetiva tasa de letalidad.

\subsection{Comportamiento de la pandemia a nivel municipal}

El comportamiento en los casos y muertes a nivel de municipios, genera escenarios importantes para diversos análisis y toma de decisiones de manera integral: Es el Distrito Central el que presenta la mayor cantidad de casos con un $26.8 \%$ y la mayor cantidad de muertes con un $29.6 \%$ del total (Figura 5).

Son diez los municipios que encabezan con mayor cantidad de casos y muertes por COVID-19, lo que indica que la cantidad de casos está en línea con el dato de letalidades. Los infectados entre el rango de edad 21-40 años representan el $47.8 \%$ del total de los casos y los principales portadores del virus.

\subsection{Proyecciones en base a los datos oficiales}

Las proyecciones en casos confirmados y muertes por la pandemia se mantendrán en crecimiento según el escenario actual. Para lograr normalizar los escenarios predictivos es necesario establecer un mejor y más adecuado control de los datos que hemos sugerimos anteriormente, solo de esta forma, con datos concretos y debidamente normalizados se pueden tomar decisiones y tener conocimiento claro de la realidad de la enfermedad en el país (Figura 6).

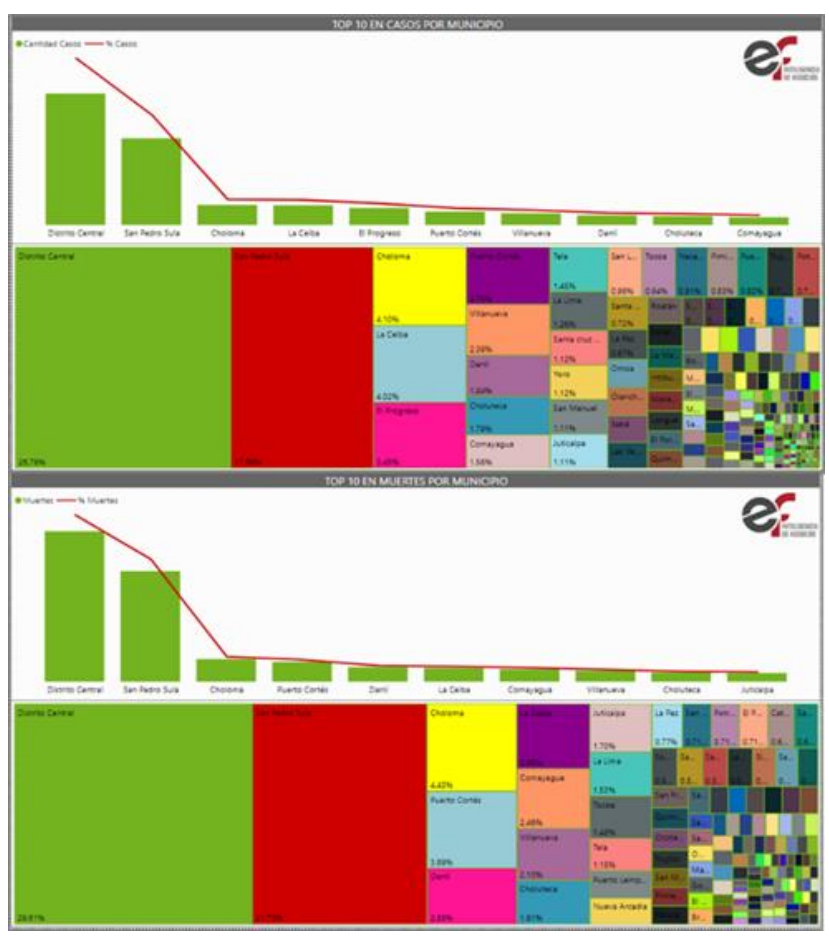

Figura 5. Participación municipal en los casos y decesos.

\section{Discusión}

Los datos oficiales publicados por la Secretaría de Salud muestran una tendencia hacia un alza en la curva de casos durante el mes de agosto en los departamentos de Cortés y Francisco Morazán, a la vez que hay una preocupante tendencia al aumento en el interior del país.

La alarma que genera esta creciente cantidad de casos confirmados de COVID-19 contrasta con la necesaria reactivación económica y social de una población que a simple vista ha visto incrementada su problemática de pobreza, miseria y marginación social. De acuerdo con estadísticas de la Secretaria de Trabajo y Seguridad Social (STSS) se perdieron en el país poco más de 500 mil empleos directos producto de la pandemia. Esto se suma al impacto que sufrió la pequeña y mediana empresa, así como la economía informal a raíz del confinamiento. Por ello urge encontrar la forma de conocer el real comportamiento de la pandemia en el país para enfrentarla de manera estratégica.

A pesar de la limitación en el número y distribución de las pruebas diagnósticas para COVID-19, las autoridades sanitarias deben analizar la distribución del virus a nivel departamental y municipal para fines estratégicos. 


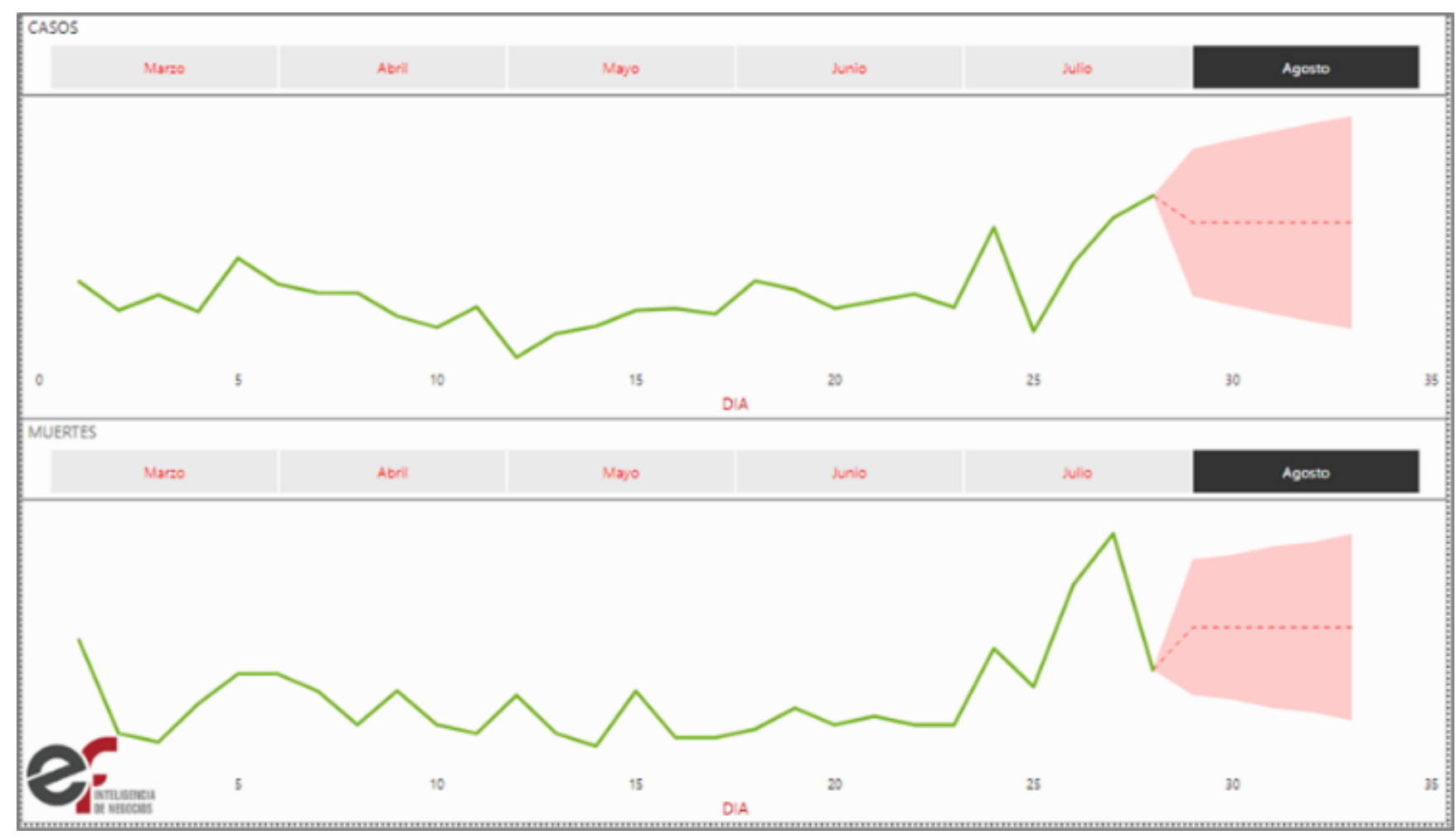

Figura 6. Proyecciones en casos y muertes. La región en rosa indica rangos mínimos y máximos a partir de agosto.

La única forma de reducir los riesgos y atrasos en la toma de decisiones basada en evidencia, como la inteligencia epidemiológica para acciones efectivas, tal y como lo recomienda la Organización Mundial de la Salud (OMS, 2020) en su documento sobre "Vigilancia de salud pública en relación con la COVID-19" publicado el pasado 7 de agosto.

Para el caso: ¿Por qué en el departamento de Cortés la proporción de contagios es alta en los hombres con alto porcentaje de muertes? Es necesario validar las tendencias en cada departamento. Eso puede hacer con inteligencia de negocios, como lo experimentó China de forma pionera en su propia epidemia (Sechi et al., 2020). No hay mucho publicado sobre inteligencia de negocios y crisis sanitarias, pero los reportes iniciales indican que puede ser útil y su potencial debe considerarse más (Loewen, 2017).

Al contar con la información ya estructurada por departamentos y municipios con recuente de casos, muertes, recuperados, edades, género y población es posible obtener cada tasa de letalidad, tasa de recuperados, tasa de población infectada y tasa de la población testeada por cada departamento y abrir el control hasta los municipios. Las estadísticas deben ser transparentes y precisas para poder guiar a los tomadores de decisiones y las políticas públicas sanitarias, más en casos de emergencia sanitaria (Pierce et al., 2020).

Es necesario que las autoridades estatales entiendan como se está comportando el virus en cada zona urbana y rural para de esta manera generar soluciones a la medida de cada departamento o municipio. Para el caso: Es importante entender porque en el Departamento de Cortés (sector urbano) la proporción de contagios y muertes en los hombres es tan alto como en zonas rurales del Departamento de Olancho, donde hay menos hombres afectados. Aunque puede haber subregistro, estas alertas deben alertar para afinar la puntería en las estrategias y planes de acción.

Sobre la tasa de letalidad, alarma que a la fecha de esta publicación, la misma sea de $3.11 \%$ a nivel nacional, más arriba del promedio de algunos países) en la región de Centroamérica (El Salvador 2.88\%, Panamá $2.15 \%$ y Costa Rica $0.97 \%$ y levemente superado por Guatemala $3.67 \%$ de acuerdo a cifras oficiales de la Secretaria de Salud de estas naciones) (Johns Hopkins, 2020; Barria et al., 2020).

En relación con los casos letales hay también serios desbalances, a diario los medios de comunicación transmiten las versiones hospitalarias sobre decesos masivos en los centros asistenciales, cifras alarmantes que se quedan a nivel de sospecha porque se dan sin haberse realizado las pruebas respectivas o porque simplemente no se tienen los resultados, si estas se suman a las muertes certificadas por Salud sin duda la tasa de letalidad se elevaría a 4 ó 5 por ciento.

Sobre este tema de subregistros en Honduras, al no contar con una plataforma transparente de recolección de datos y salidas de información es muy complejo realizar auditorías en los datos hasta alcanzar lo que conocemos como "la 
certeza de la información”. Países como El Salvador, Costa Rica, Panamá y Guatemala han implementado diversos tableros o dashboards dinámicos que permiten mejorar la visibilidad y ampliar el conocimiento del comportamiento y tendencia del virus en cada área del país, por esto se asignan recursos de manera inteligente para implementar efectivos cercos epidemiológicos. Nicaragua cuenta con uno organizado por sectores ciudadanos (Observatorio COVID19 Nicaragua).

Los datos oficiales sobre las pruebas diagnósticas indican la necesidad de aplicar mayor cantidad de pruebas a nivel nacional. La validación laboratorial permitirá una mejor visibilidad de la distribución de la enfermedad y con ello fortalecer medidas efectivas como los cercos epidemiológicos y otras que se han recomendado por parte de la OMS. Sobre este aspecto, con mucha insistencia se ha venido recomendando a las autoridades de la Secretaria de Salud incrementar los operativos de brigadas médicas casa por casa para identificar a los portadores del virus en etapa temprana y evitar que estos lleguen a los hospitales y si bien estas son regulares en barrios y colonias de Tegucigalpa y San Pedro Sula, no se están haciendo las pruebas rápidas para al menos a un miembro de cada familia visitada, lo que minimiza la posibilidad de éxito que pueden tener.

Las proyecciones para los meses subsiguientes no distan mucho de los anteriores: los casos positivos y la letalidad seguirán en incremento, difícilmente podremos observar el famoso pico de la pandemia o el aplanamiento de la curva. Los datos oficiales no son un punto de partida infalible. Aunque el colapso del sistema hospitalario parece disminuir, a la vez hay gran presión mediática y social por fortalecerlo y para habilitar opciones como centros de triaje. La explicación de la dispersión en la atención de los casos, es que ha sido efectivo acercar la atención primaria a la gente en las comunidades. Esta es una estrategia utilizada en varios países del mundo y Latinoamérica, como Chile, Costa Rica, Ecuador y México, pero que no debe dar la falsa impresión de disminución de los casos (John, et al., 2020; Maves et al, 2020; Benitez et al., 2020).

Es importante mencionar que es urgente que el Estado hondureño implemente plataformas transparentes para el almacenamiento adecuado de estos datos que se generan a diario sobre la pandemia. Esto debe hacerse con el objetivo de auditar los mismos y que la población tenga acceso mediante tableros dinámicos para entender adecuadamente el comportamiento de la pandemia en relación a los casos de muertes, recuperados, activos y sus diversas tasas incluyendo positividad en pruebas a nivel de país, departamentos, municipios, colonias, barrios, edad y género. Esto ya lo están implementando el resto de países en la región de Centroamérica atendiendo recomendaciones de la OMS a fin de establecer protocolos y formularios para que los datos puedan recopilarse y compartirse de forma rápida y sistemática en un formato que facilite la agregación, la tabulación y el análisis en diferentes contextos.

\section{Conclusión}

En crisis como la actual, los datos abiertos son necesarios en función de transparencia y ejercicio ciudadano en cada uno sus ámbitos, sanitario, legal, económico financiero, educación, empleo, sostenibilidad de las inversiones y otros que se han visto directamente afectados por la emergencia y por las malas decisiones adoptadas desde el gobierno.

Es recomendable para el país y sus ciudadanos contar con una plataforma veraz, eficiente y transparente de los datos que se generan a diario con el fin de auditar los mismos y entender adecuadamente el comportamiento de la pandemia como ya se ha implementado en otros países de la región. Este tipo de información sistematizada y comprobada es fundamental nos solo para el gobierno, también para la empresa privada y población en general para tomar las mejores decisiones en tiempo y forma de cara a lo que se viene.

Aparte de la limitación y los sesgos en los datos oficiales sobre la pandemia, Honduras enfrenta cuestionamientos intensos sobre el manejo de esta emergencia sanitaria por el $S A R S-C o V-2$ debido a la baja cantidad de pruebas diagnósticas, la alta mora en los resultados de las mismas y las carencias en recursos y la gestión estatal. La estadística epidemiológica en combinación con trasparencia y herramientas de inteligencia de negocios son una alternativa accesible para el manejo inteligente de estas crisis sanitarias (Moon et al., 2020). En suma, agregar la inteligencia de negocios es una nueva opción para acelerar estos procesos de inteligencia epidemiológica en el sistema sanitario durante la pandemia COVID-19.

\section{Contribución de los Autores}

Ambos autores participaron por igual en la recolección de datos, en la revisión de la literatura incluida y redactaron el manuscrito.

\section{Reconocimientos}

A los colaboradores académicos, autoridades de salud y autoridades locales que colaboraron en el proceso de este estudio.

\section{Conflictos de Interés}

Los autores no tienen ningún conflicto de interés relacionado a este trabajo.

\section{Referencias Bibliográficas}

Benítez, M. A., Velasco, C., Sequeira, A. R., Henríquez, J., Menezes, F. M., \& Paolucci, F. (2020). Responses to COVID-19 in five Latin American countries. Health Policy and Technology, 449. Advance online publication. https://doi.org/10.1016/j.hlpt.2020.08.014 
Expediente Público (2020) Los cementerios Covid-19 y el subregistro de muertes empiezan a hacer mella en las cifras de la pandemia en Honduras. https://expedientepublico.org/los-cementerios-covid-19-yel-subregistro-de-muertes-empiezan-a-hacer-mella-en-las-cifras-de-lapandemia-en-honduras/

Despacho de Comunicaciones y Estrategia Presidencial Honduras. (2020). COVID-19 Honduras-OFICIAL | Coronavirus en Honduras. https://covid19honduras.org/

Hola News. (2020). Funcionaria hondureña se queja por limitaciones para pruebas de COVID-19. https://holanews.com/funcionaria-hondurenase-queja-por-limitaciones-para-pruebas-de-covid-19/

John, J., Council, L., Zallman, L., \& Blau, J. (2020). Developing an Intensive Community Covid-19 Management Strategy: Helping Our Patients Access Patient-Centered Care across a Continuum of Covid-19 Disease Needs. Nejm Catalyst Innovations in Care Delivery, 10.1056/CAT.20.0181. https://doi.org/10.1056/CAT.20.0181

Johns Hopkins University. (2020). Coronavirus COVID-19 Global Cases by the Center for Systems Science and Engineering (CSSE). https://gisanddata.maps.arcgis.com/apps/opsdashboard/index.html\#/bd a7594740fd40299423467b48e9ecf6

Loaiza, J. R., Rao, K., Eskildsen, G. A., Ortega-Barria, E., Miller, M. J., \& Gittens, R. A. (2020). COVID-19 pandemic in Panama: lessons of the unique risks and research opportunities for Latin America. Revista panamericana de salud publica $=$ Pan American journal of public health, 44, e86. https://doi.org/10.26633/RPSP.2020.86

Loewen, L., \& Roudsari, A. (2017). Evidence for Busines Intelligence in Health Care: A Literature Review. Studies in health technology and informatics, 235, 579-583.

Maves, R. C., Downar, J., Dichter, J. R., Hick, J. L., Devereaux, A., Geiling, J. A., Kissoon, N., Hupert, N., Niven, A. S., King, M. A., Rubinson, L. L., Hanfling, D., Hodge, J. G., Jr, Marshall, M. F., Fischkoff, K., Evans, L. E., Tonelli, M. R., Wax, R. S., Seda, G., Parrish, J. S., ... ACCP Task Force for Mass Critical Care (2020). Triage of Scarce Critical Care Resources in COVID-19 An Implementation Guide for Regional Allocation: An Expert Panel Report of the Task Force for Mass Critical Care and the American College of Chest Physicians. Chest, 158(1), 212-225. https://doi.org/10.1016/j.chest.2020.03.063

Microsoft. (2020). Power BI Desktop. Downloads. https://powerbi.microsoft.com/es-es/desktop/.

Moon M. J. (2020). Fighting COVID-19 with Agility, Transparency, and Participation: Wicked Policy Problems and New Governance Challenges. Public administration review, 10.1111/puar.13214. Advance online publication. https://doi.org/10.1111/puar.13214
Observatorio COVID-19 Nicaragua. (2020) COVID-19 en Nicaragua, actualizado al 02/09/2020. https://observatorioni.org/.

OPS. (2020). Definiciones de casos para la vigilancia COVID-19 - 7 de agosto de 2020. https://www.paho.org/es/temas/coronavirus/broteenfermedad-por-coronavirus-covid-19/definiciones-casos-paravigilancia.

OPS. (2020) Hoja de Recursos COVID Honduras. https://www.paho.org/es/hoja-recursos-covid-19-honduras

Organización Mundial de la Salud. (2020). Vigilancia de salud pública en relación con la COVID-19: orientaciones provisionales, 7 de agosto de 2020. Organización Mundial de la Salud. https://apps.who.int/iris/handle/10665/334000. License: CC BY-NCSA 3.0 IGO

PAHO/WHO. (2020). Cumulative suspected and confirmed COVID-19 cases reported by countries and territories in the Americas, as of 3 April 2020. https://www.paho.org/en/documents/cumulative-suspected-andconfirmed-covid-19-cases-reported-countries-and-territories-8

Pearce, N., Vandenbroucke, J. P., VanderWeele, T. J., \& Greenland, S. (2020). Accurate Statistics on COVID-19 Are Essential for Policy Guidance and Decisions. American journal of public health, 110(7), 949-951. https://doi.org/10.2105/AJPH.2020.305708

Secretaría de Salud. (2020). Datos Estadísticos COVID-19. http://www.salud.gob.hn/site/

Sechi GM, Migliori M, Dassi G, Pagliosa, A., Bonora, R., Oradini-Alacreu, A., Odone, A., Signorelli, C., \& Zoli, A. (2020). Business Intelligence applied to Emergency Medical Services in the Lombardy region during SARS-CoV-2 epidemic. Acta Biomed, 91(2):39-44. Published 2020 May 11. doi:10.23750/abm.v91i2.9557

Sistema de Gestión de Riesgos (SINAGER). (2020). Coronavirus COVID19 En Honduras. https://covid19honduras.org/

Weng, C., Horby, P.W., Hayden, F.G., \& Gao, G.F. (2020). A novel coronavirus outbreak of global health concern. The Lancet, 395(10223), 470-473.

Zuniga-Moya, J. C., Norwood, D. A., Romero Reyes, L. E., Barrueto Saavedra, E., Diaz, R., Fajardo, W. C., Pineda, A., Torres, D., Barahona, R., Leiva, S. O., Hernandez, P. X., Silva, H., Leiva, C. R., Estrada, L., Barahona-Campos, A., \& Gordon, A. (2020). Epidemiology, outcomes and associated factors of COVID-19 RT-PCR confirmed cases in the San Pedro Sula Metropolitan Area, Honduras. Clinical infectious diseases: an official publication of the Infectious Diseases Society of America, ciaa1188. Advance online publication. https://doi.org/10.1093/cid/ciaa1188. 